\title{
Diablotextron
}

\section{Ese tiempo que avanza a trompicones ${ }^{1}$}

\author{
ALFONS CERVERA \\ ESCRITOR
}

No me empeñé en saber. Además, con la muerte del abuelo se cortó la relación. Erich Hackl. Boda en Auschwitz

¿Para qué volver la vista atrás? Max Aub. Los Muertos

Peregrino entre dos ciudades la de la Memoria y la del Deseo Manuel Vázquez Montalbán. Ciudad

La historia se escribe siempre con $\mathrm{h}$ minúscula. Si es con h mayúscula, entonces estamos hablando de otra cosa. De otros acontecimientos. De otros protagonistas. De algo que, como más o menos decía Max Aub de la vida, se ha convertido en un espectáculo. Lamentablemente la historia siempre ha aparecido - o casi siempre- convertida en espectáculo. O sea: a lo grande. Pero hay historias que nunca se escribieron a lo grande, que nacieron y fueron creciendo a escondidas, medio a oscuras entre la artificiosa luminosidad de los escenarios: definitivamente abandonadas a la intemperie del olvido. O aún peor: a la clandestina invisibilidad de su inexistencia. Lo que no se nombra es como si no hubiera existido. Lo he escrito -lo hemos escrito muchas veces-y hay que

\footnotetext{
${ }^{1}$ Diablotexto Digital le agradece a Alfons Cervera su deferencia al ceder este texto inédito para su publicación en el primer número de la revista. Fue presentado en el I Congreso Direcciones de la literatura contemporánea y actual (Universidad de Alcalá, 4-6 de abril de 2016). Próximamente el autor prevé incluirlo en un volumen recopilatorio de ensayos: Yo no voy a olvidar porque otros quieran (Barcelona: Montesinos).
} 
seguir escribiéndolo. Como dijo en uno de sus terriblemente hermosos poemas Gil de Biedma, después de la guerra llamada civil, fratricida, y no sé con cuántos eufemismos más, después de esa guerra, decía el poeta, media España ocupaba España entera. Hasta hace muy poco tiempo esas seguían siendo las medidas topográficas de nuestro país. Media España hablaba y la otra media se quedaba sin palabras, vivía callada, como se callan los muertos para que los dejen tranquilos.

$Y$ es que la primera cacería que organizan las dictaduras es la de la palabra. Y así fue durante los años inacabables del franquismo. Sólo una voz la suya - sonaba en todas partes. En la calle. En las casas. En los libros. En los cines. En los teatros. En la propia conciencia de la derrota sonaba a ratos la palabra que la condenaba a ser culpable porque —digamos lo que digamosno hay nada menos honorable que un vencido. $Y$ en la propia encarnadura de esa derrota se clavó con una saña casi inexplicable el sentimiento irreductible de la culpa. La historia fue durante esos años escrita con mayúscula. La otra se quedaba, como decía antes, en el reducido espacio de la clandestinidad, de las cenas pegadas a la radio extranjera, de algunos libros y películas que nos hablaban con el lenguaje cifrado de los signos, de los sueños que como todos los sueños nos engañaban como a chinos.

La palabra. Lo que nos junta a tanta gente para que no se nos hunda sin remedio en los profundos, injustos, atolladeros del silencio y el olvido. Ya he dicho que la palabra es el primer cuerpo muerto que cuelga de los ganchos carniceros en los escaparates de la dictadura. Nos la han ido cambiando a su antojo, al antojo de un orgullo rancio, de ese orgullo viejo que ostentan siempre los que ganan en una batalla, en una guerra, en la manera que habría de ser diversa - y nunca única y excluyente- a la hora de contar lo que nos pasa. "El franquismo no sólo se apropió de la historia y de la memoria sino que también corrompió las palabras. Existe una fortísima tendencia interior que nos mueve a hablar de asesinatos cuando nos referimos a las víctimas de derechas y de fusilamientos cuando se trata de las de izquierdas. $Y$ si esto pasa incluso en gente consciente de la trampa, estamos sencillamente ante la interiorización colectiva de la ideología franquista". No lo digo yo. Lo dice el historiador 
Francisco Espinosa Maestre en uno de sus múltiples, exactos, radicalmente rigurosos testimonios sobre la represión.

Qué poco han cambiado las cosas cuando hablamos de lo que fue ese tiempo histórico que arranca con la II República, continúa con el golpe de Estado fascista y la guerra, con la dictadura franquista y acaba -o no acaba, yo creo que no- con la transición política a la democracia. Es evidente que en lo que duró la dictadura era imposible hablar otro lenguaje que el de los vencedores. Eso nadie lo duda. Lo que empieza a ser más contradictorio es si, cuando llegan la transición y los sucesivos gobiernos socialistas, ese lenguaje y la construcción de una democracia fuerte habrían de ser necesariamente los mismos. Y lo son. Con los matices que queramos, pero los lenguajes y la construcción de esa democracia se organizan sobre la base no siempre justificada de las renuncias. Alguien dirá que todos hubieron de renunciar a parte de lo que fueron. Yo creo que unos renunciaron más que otros. Quienes fueron franquistas hasta entonces y quienes fueron todo lo contrario se juntan en una pérdida de identidad que convierte ese tiempo en un tiempo de disfraces. Ya no se sabe qué es cada cual. Ya no se sabe qué se defiende desde posiciones que a simple vista deberían de ser antagónicas para dejar claro que un país y un tiempo son una mezcla —-pero no revuelta - de países y de tiempos. Pero aquí no se dio eso. Aquí la cultura del franquismo siguió en su larga, inacabable duración hasta bien entrada la democracia. ¿Hasta hoy mismo se alarga esa duración? Posiblemente sí.

Decía un viejo anarquista de mi tierra hace muchos años: "Mires pande mires to es mortífero". Recuerdo esas palabras y es como si no hubiera pasado el tiempo. Cuarenta años de dictadura han servido para que los cambios políticos choquen contra una obviedad, una triste obviedad: en este país no se ha hecho una auténtica ruptura con la cultura del franquismo. Hay un chiste muy cruel que lo explica: toda España es de derechas, lo que pasa es que media España lo sabe y la otra media no lo sabe. Como dice Chavela Vargas del cuerpo y el alma, en esa maravilla de canción que es Las ciudades, la cabeza de la gente se llenó de hielo y frío en aquella larga noche de la dictadura. Y nos dejó para el arrastre. Por eso en los momentos del cambio que estamos viviendo no hay manera de avanzar en esos itinerarios de libertad individual y colectiva que los tiempos de 
ahora necesitan para salir de esa cultura que viene de los tiempos remotos, como los dinosaurios y las arañas gigantes de las películas de terror.

Lo escribía Juan Gelman pensando en otra cosa parecida: "No nos dejan vivir / esas vergüenzas no nos dejan vivir". Los cambios adelante ponen de los nervios a esta democracia. O a una buena parte de esta democracia. No acaban de deshacerse las viejas ataduras, cualquier leve intento de novedad política es entendida por quienes se anclan a los viejos tiempos como una ofensa. El código penal casi viene de aquel tiempo en que la ciencia se tenía que arrodillar para que el fanatismo religioso pasara por encima de su arrepentimiento o su cadáver. Los tiempos de antes y los de ahora tienen por desgracia — como vemos cada día en los medios de comunicación- demasiadas cosas en común.

Y aún otro testimonio, esta vez en la robusta escritura de mi inolvidable amigo Rafael Chirbes: "El pacto que se les propuso a los españoles, bajo el razonable argumento de cambiar pasado por futuro, fue un cambio de ideología por bienestar; es decir, un trueque de verdad por dinero. Y el país lo aceptó". Como había aceptado — salvando las distancias de tiempo y circunstancias - la gramática del daño aquel verano de 1969 en que Max Aub regresó a España pensando en un país que ya no era el que imaginaba en su destierro mexicano, un regreso amargo del que saldría esa obra maestra de la rabia que es La gallina ciega. Sí, el país aceptó cuando la transición esa verdad que, como explicaba Foucault, emana del poder, de esa capacidad que el poder tiene para fabricar su verdad, una verdad que hará extensiva a los ojos, oídos y conciencia de una ciudadanía que no ha abandonado su condición de súbdita porque las sirenas de la concordia - aunque se trate de una falsa concordia que esconde subrepticiamente las contradicciones - acaba adormeciendo las conciencias. Veamos, si no, otro testimonio imprescindible si queremos entender en toda su complejidad y magnitud lo que intento explicar. Lo escribe Victor Klemperer en sus memorias a ratos escalofriantes del nazismo: uno de los éxitos de las tiranías — dice Klemperer- consiste en "la represión del afán de preguntar".

La historia avanzaba pues lentamente o, según se mire, a velocidad de vértigo. La transición seguía incrustada en la cotidianeidad de una época que poco quería saber de sobresaltos. España había pasado de una Monarquía a 
una República, después a una dictadura y finalmente a otra Monarquía sin que se le moviera un pelo del tupé posmoderno que hubiera envidiado el mismísimo Elvis Presley cuando iniciaba los primeros compases de su inigualable Hotel de los corazones rotos. $Y$ ahí estamos. Tan tranquilos. Como si todo entrara dentro de una normalidad que en realidad es una absoluta anomalía.

Contar esa anomalía es nuestro trabajo. Escarbar en el pasado para sacar de él la mejor materia para el aprendizaje. Cuando hablamos de pasado estamos hablando en realidad de los usos que hacemos de ese pasado. Ahí existe la distinción entre una y otra manera de acercarnos a lo de antes. La única condición que habríamos de contemplar en esos diversos usos y acercamientos habría de ser la de no mentir. Ya sé que eso es muy relativo, como todo en la vida. Ya sé que alguien dirá que no hay más verdad que la de cada cual, que es muy difícil separar el grano de la verdad de la paja de los intereses particulares o de grupo. Pero algo hemos de hacer para que el grano y la paja queden claros a la mirada curiosa de quienes nos leen, de quienes nos escuchan, de quienes nos ven de frente o de perfil contando nuestras propias versiones de la historia. El pasado no se fabrica, está ahí para que lo movamos de sitio, para traerlo a los tiempos de ahora, para sacar de él lo que más nos puede enseñar acerca de lo que nos pasa. Hay tres vértices fundamentales para esa recuperación —que habría de ser siempre crítica- del pasado: la historia, la memoria y la ficción. Las tres en una sola manera de andar —aunque sea de puntillas - por el complejo itinerario del pasado. Antes, hasta hace bien poco, las tres andaban por separado. Cada una a su bola, sin hacer caso una de las demás, sin que una puesta en común de lo que perseguía cada una pudiera ser posible para que esa verdad a la que antes me refería no fuera una tarea imposible.

Mi aportación al debate, a esa posibilidad de trabajo colectivo para indagar en lo que fuimos, se ha producido desde el territorio de la novela. Soy escritor de ficciones. Invento lo que creo que pasó para comprobar si detrás de lo que inventamos —o delante- habita una realidad que, paradójicamente, resulta más confusa fuera de las novelas que en unas páginas sólo sujetas a la imaginación de quien las escribe. La realidad construida por la imaginación no es menos real que la que la vida nos ofrece cada día. Cuando escribí la novela Maquis, hace 
casi veinte años, yo no sabía nada de la guerrilla antifascista que luchó en los montes de mi tierra. Me lo inventé todo, absolutamente todo. Incluso hay errores históricos y de funcionamiento de la propia guerrilla que aún hoy me ruborizan. Sin embargo, al poco de publicarse esa novela tuve la oportunidad de conocer a todos los hombres y mujeres del monte. Y me llamaba la atención lo que decían: "Es como si hubieras estado con nosotros en la guerrilla". Se referían a la "verdad" de lo que yo contaba. Sin embargo, poco a poco, conforme iba hablando más tiempo con ellos, comprobaba que mi novela se parecía poco a lo que realmente vivían luchando en las montañas. Hasta que un día lo descubrí, descubrí en qué consistía aquella alusión suya a la exactitud biográfica de mi relato de ficción. En realidad lo que ellos habían leído en la novela no era su vida diaria entre rocas escondidas y soledades infinitas. En realidad lo que ellos y ellas habían leído en mi novela era todo aquello que habían estado soñando en sus largos años de lucha escondida bajo las miradas atónitas de las liebres. Tantos años sin una vida normal, tantos años sin poder bailar un domingo en las verbenas de los pueblos, tantos años de no desnudarse y aún menos para compartir una noche de amor con sus novios o sus novias, tantos años -en fin- de no saber qué les esperaba al otro lado de los sueños. Todo esto sucedió después de que yo me adentrara — con muchos puntos de inconsciencia y falta de pudor- en los territorios siempre abruptos de la memoria. $Y$ todo eso, después de leerlo muchas veces en las páginas imprescindibles de mi querido y admirado José Manuel Caballero Bonald, lo encontré de nuevo, no hace mucho, en una novela de John Banville: "Imágenes del pasado remoto se agolpan en mi cabeza, y la mitad de las veces soy incapaz de distinguir si son recuerdos o invenciones". Aquí vemos la esencia de la ficción cuando nos acercamos a la historia. Lo que inventamos juega un papel fundamental en el proceso de recuperación del pasado, en la necesidad de construir una historia que sea lo menos engañosa posible, que al menos no nos avergüence en el caso de que resulte insuficiente o con lagunas en su relato más o menos espectaculares.

El tiempo discurre a su antojo, existe como una convención que admite pocas interrupciones, se cuenta a sí mismo y nosotros sólo somos sus voceros, sólo eso para que en el camino desde el principio del relato ese tiempo se hunda 
lo menos posible y pueda seguir un orden continuo o discontinuo según si lo traemos a colación desde la historia o desde esa intemperie desapacible que siempre serán el relato memorialista y la ficción. La intemperie. Aquí otra cualidad de la ficción y la memoria. Hace falta recordarlo siempre. Escribir desde el recuerdo, inventar ese recuerdo, es algo que sucede a la intemperie. No hay relato seguro cuando echamos mano de la imaginación o los recuerdos. Lo que hay debajo es una vasta extensión de arenas movedizas, de un lodazal dispuesto a ahogar tus intenciones, de esa hidra de siete cabezas siempre decidida a cortarte la tuya como si fueras uno de aquellos revolucionarios que acabaron traicionando su revolución. Escribir es en sí mismo un acto de insolencia. Y más aún si la escritura tiene lugar en un país que sigue siendo, después de tanto tiempo, un país miedoso a la hora de contarse a sí mismo lo que pasó hace apenas unos años.

Vuelvo a Espinosa Maestre cuando toma prestada la voz de Agustín Gómez Arcos: "La dictadura franquista imponía el silencio, la democracia impide la memoria". Resulta inquietante escuchar lo que escuchamos con demasiada frecuencia: lo que intentamos algunos novelistas es reabrir las heridas del pasado. Ignoran aposta, quienes eso advierten, que no se puede reabrir lo que nunca fue cerrado. Tal vez ahí resida la intención nada violenta que empuja la escritura -al menos la mía-: intentar un relato que ayude a completar el itinerario de una memoria anclada en el anacronismo de una victoria antigua, una victoria que se quiere perpetuar entre nosotros como el único paradigma de la dignidad en nuestra última historia. Completar el ciclo, pues, nunca cerrarlo porque ningún relato puede arrogarse la cualidad de ser el último y aún menos el más definitivo. Pero hay algo que me resulta sospechoso en el espacio de los textos de ficción: parece que los únicos escritores que cumplen de verdad una labor terapéutica en esto de cerrar las heridas del pasado son los que apuestan por un relato igualitario entre las dos memorias. Ya saben a qué me refiero. Seguro que les suena aquello ya tan extendido de la equidistancia. Es más, ahora mismo ese grupo de escritores ha descubierto un espacio propio donde desarrollar sus teorías: la Tercera España. Y aseguran, ese descubrimiento, con dos puntales sacados de la manga en tiempos diferentes. Antes - hace unos 
años - fue Dionisio Ridruejo uno de esos puntales. Desde hace no mucho el otro puntal, aireado hasta la extenuación como en un anacrónico estribillo veraniego del inefable Georgie Dann, es Chaves Nogales. Todo vale a la hora de apuntalar el andamiaje de una nueva visión del pasado para que nada quede sin asegurar a ras de sus propios intereses ideológicos. Cierto que fue Paul Preston quien usó el término Tercera España, no sé si el primero pero sí, tal vez, con mayor consistencia que sus imitadores desde su incuestionable rigor de historiador fuera de toda sospecha. Pero ese término, en los textos y declaraciones de los escritores a que hago incógnita referencia, es una manera de escurrir el bulto a la hora de señalar responsabilidades en el inicio de ese desastre que fue la Guerra Civil española. En esa recurrencia a un tercer vértice que completa los que suponen la II República y el fascismo hay la intención de reclamar para la legalidad republicana el origen de todos los males que todavía hoy sufrimos en este país desmemoriado. $Y$ aún hay una intención igualmente perversa en sus intenciones: llegar a sustituir con sus trabajos de ficción el papel que corresponde en buena lógica a los historiadores.

Por eso decía que la ficción -al menos algunas ficciones entre las que se cuentan las mías- se produce en la intemperie. No hay estrategias cerradas que nos lleven —ni a quien las escribe ni a quien atentamente las lee- a ningún paisaje tranquilizador. El relato que me interesa es el que acaba con más dudas que las que mostraba a la hora de empezar. El que no se urde para convencer a nadie sino para invitar a una reflexión cuanto más amplia mejor. El relato que se construye no para decir la última verdad sino para intentar, con todas mis fuerzas de novelista siempre en período de aprendizaje, que ya la primera línea que escribo no sea una mentira. Invento a partir de nada: un destello en medio del insomnio, aquel gesto reflejado en un espejo de la casa familiar, el traqueteo de un fantasma que son todos los miedos que habitaron el desprotegido sueño de la infancia, la pequeña mancha de humedad en la pared donde alguna vez hubo un cuadro de mercadillo con un paisaje de ríos azules y caballos. Invento para salir, aunque sea lentamente, a paso de tortuga, de ese silencio espectacular que —como dice Imre Kertész- siempre tiene algo de misterioso. Ir paso a paso - y ahora hablo de la escritura como oficio, como ese noble oficio 
que nos dignifica o nos hunde en la miseria-, ir paso a paso, digo, también te permite aquilatar tu propia ignorancia de los hechos que cuentas para dotar a esa ignorancia de un andamiaje narrativo que le permita mantenerse en pie como obra literaria: más o menos, eso que antes decía sobre cómo se urdió mi novela sobre la guerrilla antifascista. O lo que me gusta repetir hasta la saciedad allá donde acudo para hablar de las ficciones. Me refiero a Faulkner cuando decía que el novelista escribe de lo que ignora más que de aquello que conoce.

Regreso al principio de esta exposición. La historia se escribe con letra minúscula. El tiempo también es el tiempo pequeño de los pequeños acontecimientos. Sin embargo, este país se sigue contando a sí mismo y a quien quiera escucharlo una historia a lo grande. La transición política a la democracia convirtió el tiempo de antes y el que vino luego en un apaño escrito con la $\mathrm{C}$ inmensamente desproporcionada del consenso. Y ahí estamos, como si Franco se hubiera muerto ayer y no hace más de cuarenta años. Como si aún resultara difícil crecer adultamente si no es bajo el palio $-\mathrm{y}$ nunca mejor dicho si atendemos a la poderosa influencia de la Conferencia Episcopal en una España aconfesional- de su devastadora memoria. Como si escribir mientras caen chuzos de punta en el teclado del ordenador fuera un acto de rebeldía destinado a verse sentado en el banquillo de los acusados. Como si hubiera otra escritura que no sea la de la subversión. Como si vivir tuviera que ser necesariamente una caterva de traiciones. Como si el tiempo que viene de antes, de cuando todo era una abyecta manera de vivir contra la razón y el sentido más justo de lo humano, fuera el único tiempo posible y no el peor que durante tantos años sufrió este país, un país que está siendo escrito con las letras -éstas sí, enormemente grandes- de la desmemoria, el silencio y el olvido.

Escribimos para que esas letras y las palabras que componen vayan reduciendo su estrambótico tamaño. Para que su difícil escritura parafraseando a Ángel González- sea la de la esperanza, aunque no disfrute de ningún consentimiento. Para que el tiempo de la infamia que viene de tan lejos pueda andar con el vigor de una nobleza que nunca hubo de resultar vencida y deje de avanzar a trompicones, como dijo en la Academia Sueca el escritor Patrick Modiano cuando recibió el Premio Nobel de Literatura. Es mi 
deseo. La voluntad de una escritura que, como decía Vázquez Montalbán, ha de ser más insubordinación que asentimiento. Ahí, en esa escritura donde se juntan a la vez y por separado la historia, la memoria y la ficción, nos encontramos. Y aquí hemos de seguir, ojalá que no por los siglos de los siglos. Ojalá que pronto el tiempo que haya de llegar —en la escritura y fuera de la escritura- sea todo lo apacible que la buena memoria se merece. 